\title{
A Parametrical Analysis for the Rotational Ductility of Reinforced Concrete Beams
}

\author{
Domenico Raffaele, Giuseppina Uva, Francesco Porco and Andrea Fiore*
}

Dicatech, Politecnico di Bari, via Orabona 4 - 70126 Bari, Italy

\begin{abstract}
The assessment of the plastic rotation of reinforced concrete beams is an essential aspect to avoid structural brittle collapses. The value actually available can be generally determined as sum of two different components. The first, due to bending, the second for inclined shear cracks. This paper presents a simplified model which provides the flexural plastic rotation of the rectangular beams with a "closed-form solution". The approach is substantially dimensionless and includes main influencing factors the cross -section, as mechanical material properties, ductility, geometrical and mechanical reinforcement ratio, confinement effects. In closing, in order to appreciate the reliability of the procedure, a comparison with models proposed by international technical standards is made.
\end{abstract}

Keywords: Vertical bending cracks, Plastic rotation capacity, Ductility, inclined shear cracks, Plastic bending hinge, mechanical reinforcement ratio.

\section{INTRODUCTION}

The current European technical rules [1-3] provide the seismic capacity of existing reinforced concrete (RC) buildings by means of non-linear analysis. These methods, however, require knowledge of the actual post-elastic rotational capacities of each structural element (beams, columns) both in monotonic field, for non-linear static analysis, and in cyclic field, for non-linear dynamic analysis. In non linear static field, a series of parameters (yielding, peak resistance, ultimate state) has to be defined, in order to define the response curve of the element, while in non-linear dynamical field, cyclic models for strength and stiffness degradation have to be defined. Nevertheless, these models are not easy to define, because they involve numerous geometrical and mechanical parameters and several uncertainties (for example the influences load types).

In order to facilitate practical applications, the methods usually adopted in technical codes only provide experimental relationships for deformation capacity at the elastic (yielding) and at ultimate (collapse) limit; therefore, based on these prescriptions, it is not possible to completely define with specific rules the strength degradation (softening branch) or the hysteretic behaviour. In addition, these relationships are based on the following principal parameters:

1. Ultimate concrete strength;

2. Ductility characteristics of the reinforcement steel;

3. Shear slenderness.

\footnotetext{
*Address correspondence to this author at the Dicatech, Politecnico di Bari, via Orabona 4 - 70126 Bari, Italy; Tel: +39 080 5963832;

Fax: +39 080 5963832; E-mails: andrea.fiore@poliba.it; ing.andfiore@gmail.com
}

Generally, the deformation capacity at yielding is evaluated as a chord rotation, taking into account different contributions corresponding to bending, shear and slip mechanisms. Therefore, it is difficult to define a relationship between the element parameters and the rotational capacity, due to the complex phenomena influencing the post-elastic deformation behaviour and to the natural variability affecting these phenomena. The code, consistently with the methodologies developed in literature, proposes two main approaches: a mechanical-empirical approach, based on plastic hinge length concept, and a purely empirical approach [410]. In addition, it should be noted that precisely defining the plastic rotation in the non-linear field is a crucial step in the seismic assessment of buildings and infrastructure [11-14].

The paper proposes a mechanical model based on dimensionless relationships which is able to examine the effects of the flexural collapse for rectangular cross-sections. The analytical/graphical approach allows to perform simple parametrical analyses and evaluate the influence of some mechanical characteristics that are usually neglected in other numerical approaches.

The following simplifications are made:

1. after the first cracking, the contribution of the tensile concrete is neglected;

2. tension-stiffening effects are disregarded.

The parameters included in the model are:

1. material constitutive laws;

2. mechanical tensile reinforcement ratio;

3. compressive-tensile reinforcement ratio;

4. post-elastic branch in the idealised moment-curvature relationship. 


\section{CONSTITUTIVE LAWS AND MOMENT-CURVA- TURE RELATIONSHIP}

Although there are aspects that fall into purely didactical fields, it is important to propose hereinafter the consolidated theories because symbols and some quantities are referred to in the proposed methodology.

The model considers two alternative stress-strain relationships in compression (Fig. 1 left). Both the laws start with a parabolic branch that exhibits the maximum stress at the yielding strain $\varepsilon_{c y}$ ( The second branch, which includes softening effect, is parabolic in the first case (indicated with symbol "P") and linear in the second one ("L"). The constitutive law for reinforcement, both in tension and in compression, is assumed to be an elastic-plastic one with hardening (Fig. 1 right). The steel elastic modulus employed in this work is equal to $E_{s}=200000 \mathrm{~N} / \mathrm{mm}^{2}$.

The methodology here proposed allows to obtain the expressions of $\theta_{p}$ as a function of a "conventional" parameter $\left(\xi^{\text {conv }}\right)$, which characterises the failure behaviour of the section. This parameter is obtained by taking into account the "conventional constitutive laws", which are slightly different from those considered in Fig. (1). The main changes consist, substantially, for concrete, at strain values $\varepsilon_{c}>\varepsilon_{c y}=2 \%$ o the compressive strength corresponding remains constant, while for reinforcement steel, $f_{t}=f_{y}$, that is, the constitutive law is without hardening.
The proposed approach completely neglects the tensile concrete strength, except for the evaluation of the cracking moment $M_{c r}$. In this case, the constitutive law is assumed as a parabolic rectangular one. Following the Guyon hypotheses, the maximum strain $e_{c r}$ is obtained as a function of the tensile reinforcement ratio. The parameter $\alpha_{t}$ determines the maximum allowable stress in tension. Generally, for $M=$ $M_{c r}$ the stress distribution is assumed in accordance with the scheme shown in Fig. (2).

In which, the resulting forces: $C_{S}^{\prime}, C_{C}, T_{C}$, and $T_{S}$ are evaluated using the following equations:

$$
\begin{aligned}
& C_{s}^{\prime}=\beta^{*} f_{y} \mu A_{s} \\
& C_{C}=k^{*} \alpha f_{c} b \xi d \\
& T_{C}=\frac{2}{3} \alpha_{t} f_{c} b(1+\delta-\xi) d \\
& T_{S}=\beta f_{y} A_{S} \\
& \varepsilon_{c r}[\%]=0.01\left\{25 \cdot 10\left[100 \frac{\omega}{(1+\delta)} \frac{f_{c}}{f_{y}}-1\right]^{2}\right\} \geq 0.25 \%
\end{aligned}
$$

Fig. (3) (left) shows the moment-curvature relationship. There are three points that completely define the law:

1. the cracking point, and the related $\mathrm{M}_{c r}$;
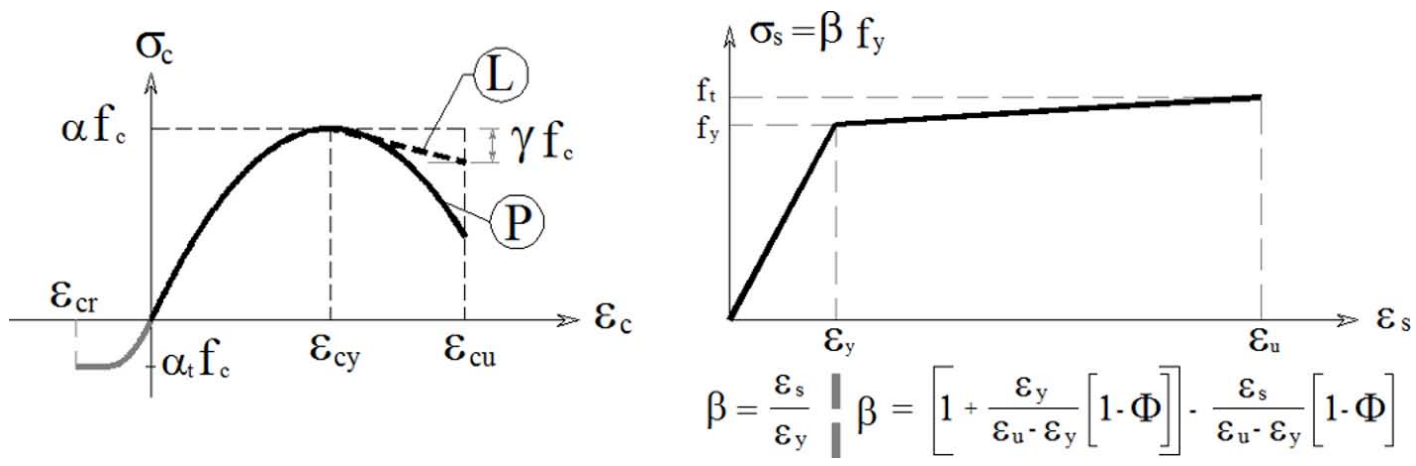

Fig. (1). Stress-strain constitutive laws for (left) concrete and (right) reinforcement steel.

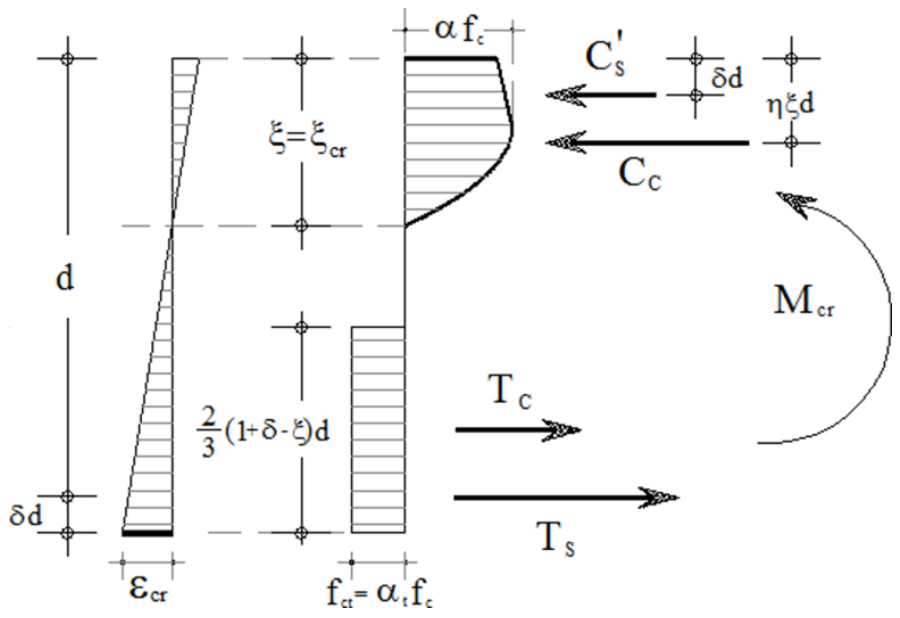

Fig. (2). Stress-strain distribution: hypotheses at cracking. 
2. the yielding point, characterised by the yielding of steel in tension, and the related $M_{y}$;

3. the ultimate point, where the ultimate strain in concrete or in steel is reached, and the related $M_{u}$.

It is known that the behaviour of an RC section, after the first cracking, essentially depends on the tensile reinforcement (Fig. 3 - right). For low values of the reinforcement ratio (curve a), the post-cracking branch II is almost coincident with a linear one, whereas the post-yielding branch III is characterised by high values of the ultimate curvature and perceptible increments of the failure moment $M_{u}$ with respect to the yielding one $M_{y}$. For higher values of the reinforcement ratio (curve b), the post-cracking behaviour (branch II) becomes non linear and the ultimate curvature approaches the yielding one. In these cases, the failure moment can be lower than the yield one $\left(M_{u}{ }^{(b)}<M_{y}{ }^{(b)}\right)$. For beams with very high reinforcement ratios, branch III can even disappear, and failure can be attained for yielding of the tensile reinforcement. Finally, in the case of superreinforced beams (curve c), also the branch II can vanish and the beam exhibits a fragile collapse at the level of the first cracking. Known three points of the law it is possible to idealize the curve considering it as a function having linear branch.

However, it should be pointed out that, in all the examined conditions, the proposed approach is based on the assumption of a linear relationship between the characteristic points. If $M_{u}<M_{y}$ (see curve $b$ and $c$ ), the post yielding branch is assumed to be horizontal and the failure point in the moment - curvature diagram is the one for which $M=M$

\section{PLASTIC ROTATION CAPACITY}

The plastic rotation capacity can be determined by evaluating the effect due to two different contributions: bending $\left(\theta_{P B}\right)$ and shear $\left(\theta_{V}\right)$.

The proposed procedure is based on the scheme of a continuous beam with uniformly distributed reinforcement, for which the rotation on an intermediate support is calculated. The zero points in the moment diagram are supposed to be symmetric on both sides of the support. The shear slenderness is assumed to be $\lambda=L_{v} / d$, where $L_{V}$ is the distance between the zero and the maximum in the moment diagram (i.e. the point of contra-flexure) (Fig. 4 - left).

The plastic rotation due to bending $\theta_{P B}$ can be determinated integrating the moment-curvature diagram between two zero consecutive points. In particular:

$$
\begin{aligned}
& \overline{\theta_{P B}}=\overline{\theta_{u}}-\overline{\theta_{y}}=\frac{d}{L_{V}}\left(\theta_{u}-\theta_{y}\right)=\chi_{c r} d\left(\frac{M_{y}}{M_{u}}-1\right) \\
& +\chi_{y} d\left(\frac{M_{c r}}{M_{y}}-\frac{M_{c r}}{M_{u}}\right)+\chi_{u} d\left(1-\frac{M_{y}}{M_{u}}\right)
\end{aligned}
$$

When a threshold shear is reached, a number of inclined shear cracks start in the plastic zone. The inclined shear cracks can dramatically increase the rotation capacity. The value of this contribution is calculated in accordance with research of Ahner and Kliver (1998) [15] (see Fig. 4 - right), introducing the dimensionless variable $\overline{\bar{\theta}}$, as a function of the parameter $a_{1}$ (which depends on the lever arm of internal forces $z$, on the compression struts inclination at the steel yielding $\beta_{S}$ and on the inclination of the stirrup reinforcement $\alpha_{t}$ ):

In the proposed model, it is assumed $\beta_{S}=45^{\circ}, \alpha_{\mathrm{t}}=90^{\circ}$, and $\alpha_{1}=0.5 z c t g \beta_{S}-\operatorname{ctg} \alpha_{\mathrm{t}}=0.45 d$.
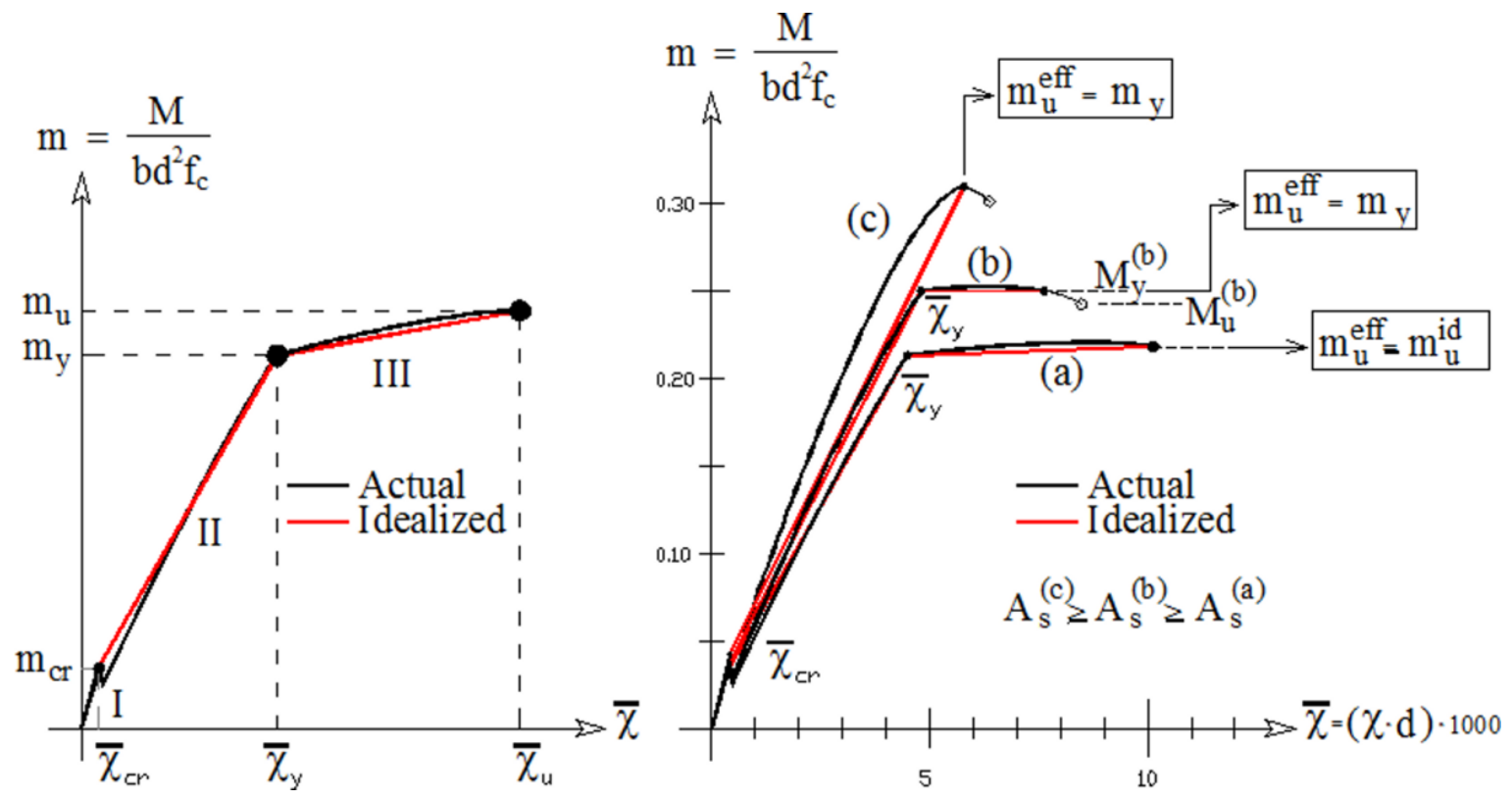

Fig. (3). Idealized and actual moment-curvature relationship for a RC section. 

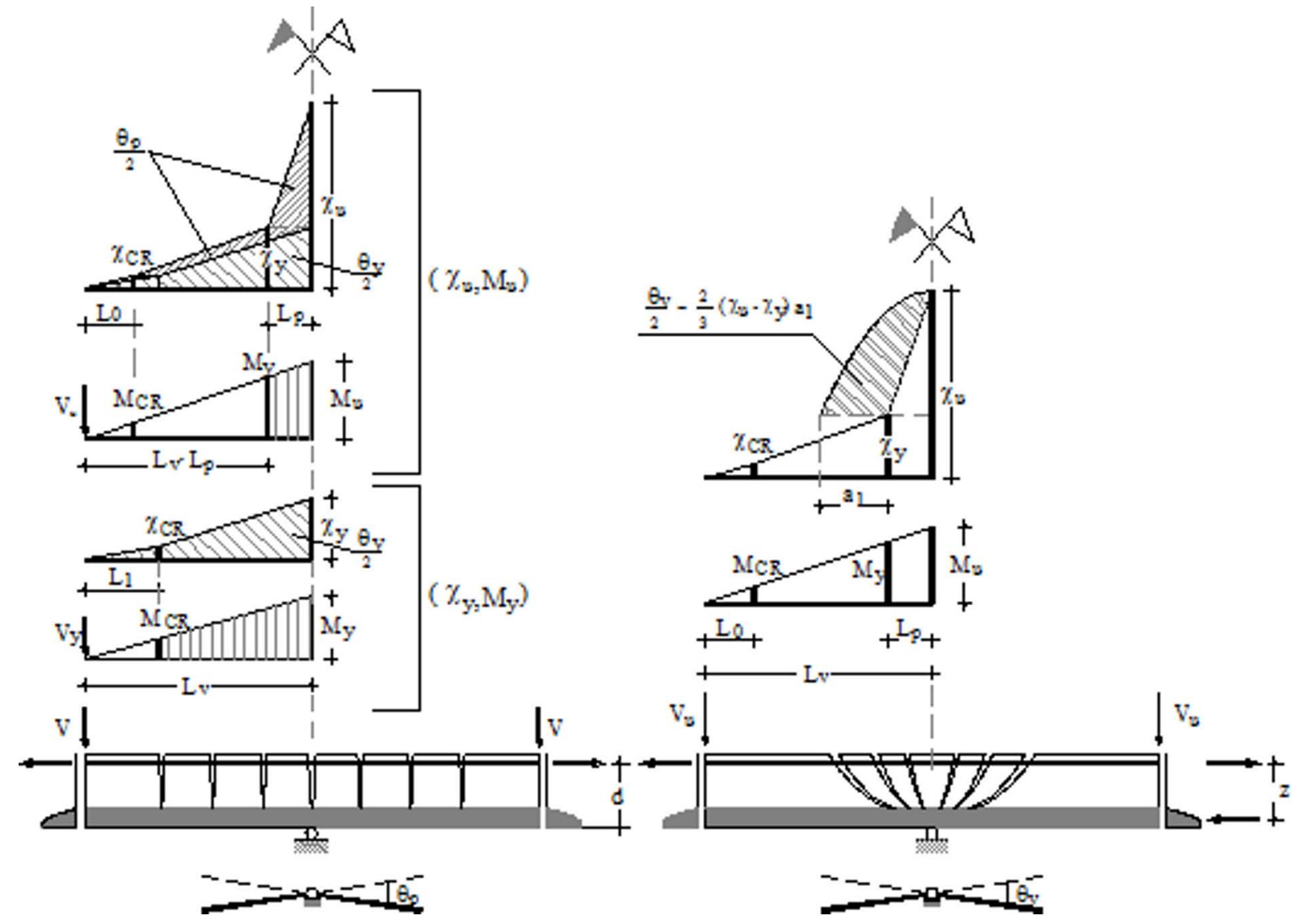

Fig. (4). Model for calculating the plastic rotation due to bending (left) and shear (right).

$\frac{4}{3}\left(X_{u}-X_{y}\right) d=\overline{\bar{\theta}}_{V}=\bar{\theta}_{V} \frac{L_{V}}{a_{1}}=\left(\theta_{V} \frac{d}{L_{V}}\right) \frac{L_{V}}{a_{1}}=\theta_{V} \frac{d}{a_{1}} \Rightarrow \theta_{V}$

$=\frac{4}{3}\left(X_{u}-X_{y}\right) a_{1}=\frac{4}{3}\left(X_{u}-X_{y}\right) \frac{z}{2}$

It is also assumed that shear cracks appear when the beam slenderness $\lambda$ becomes lower than limit slenderness given by following relation:

$\lambda_{\text {lim }}=\frac{M_{y}}{V^{*} d}$

Equivalently (for a fixed $\lambda$ ), it's possible say that shear cracks appear when $\omega \geq \omega_{\text {lim }}$ or $\xi \geq \xi_{\text {lim }}$.

For beams higher than $60 \mathrm{~cm}$, according to the prescriptions of document Bullettin CEB (1985) [16], V* can be expressed by the following relationship:

$V^{*}=\tau_{r}\left(1+50 \rho_{l}\right) b d=\tau^{*} b d$

Introducing this value in Eq. 7, the dimensionless moment at yielding is given by the following expression:

$m_{y}=\frac{M_{y}}{b d^{2} f_{c}}=\frac{V^{*}}{b d}\left(\frac{L_{V}}{d}\right)_{\lim } \frac{1}{f_{c}}=\tau^{*} \lambda_{\lim } \frac{1}{f_{c}} \Rightarrow \lambda_{\lim }=\frac{m_{y}}{\bar{\tau}}=\frac{m_{y} f_{c}}{\tau^{*}}$

The diagram in Fig. (5) gives the quantity $\bar{\tau}$ as a function of the concrete compression strength $f_{c}$.

\section{ANALYTICAL FORMULATION OF ROTATIONAL CAPACITY}

4.1. Step 1: Evaluation of $\chi_{c r}, \chi_{y}$ and $\chi_{u}$.

This step consists of the evaluation of the curvatures $\chi_{c r}$ (first cracking), $\chi_{y}$ (yielding of the tensile reinforcement) and $\chi_{u}$ (failure). They can be obtained as a function of normalized neutral axis depth $\xi_{c r}=x_{c r} / d, \xi_{y}=x_{y} / d$ and $\xi_{u}=x_{u} / d$. It is obtained:

$\overline{\chi_{c r}}(\mu)=\chi_{c r} d=\frac{\varepsilon_{c r}}{1+\delta-\xi_{c r}(\mu)}$

$\overline{\chi_{y}}(\mu)=\chi_{y} d=\frac{\varepsilon_{y}}{1-\xi_{y}(\mu)}$

$\overline{\chi_{u}}(\mu)=\chi_{u} d=\frac{\varepsilon_{u}}{1-\xi_{u}}$

failure due to maximum strain in the tensile reinforcement;

$\overline{\chi_{u}}(\mu)=\chi_{u} d=\frac{\varepsilon_{c u}}{\xi_{u}}$

failure due to maximum strain in the compressed concrete. 


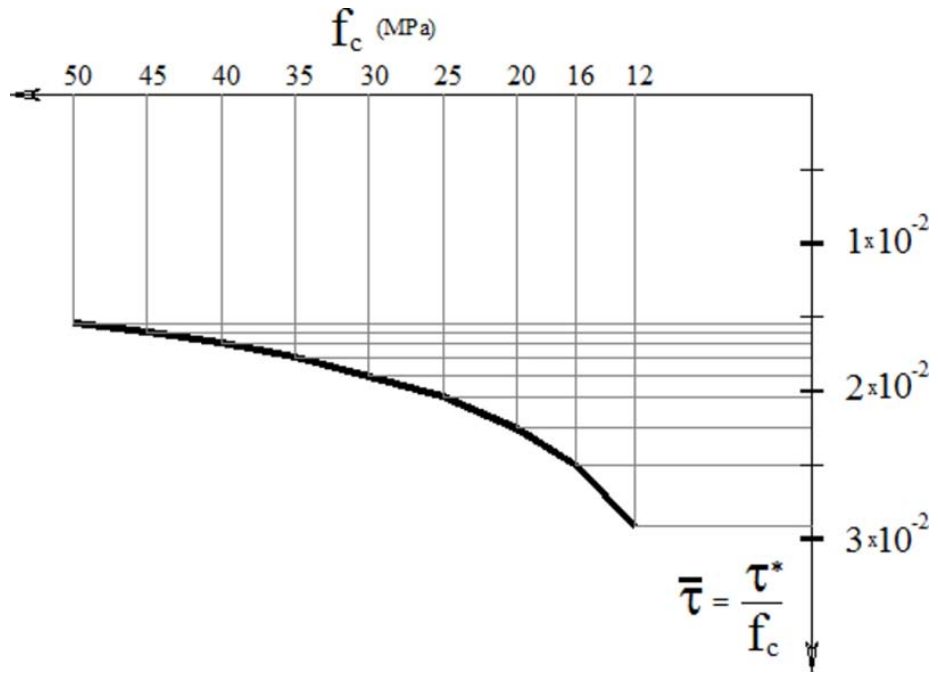

Fig. (5). $\bar{\tau}$ vs concrete compressive strength $f_{c}$.

Table 1. Definition of the Fundamental Parameters for the Evaluation of $X_{c r}, X_{y}$ and $X_{u}$ vs $\xi_{c r}$, $\xi_{y}$ and $\xi_{u}$
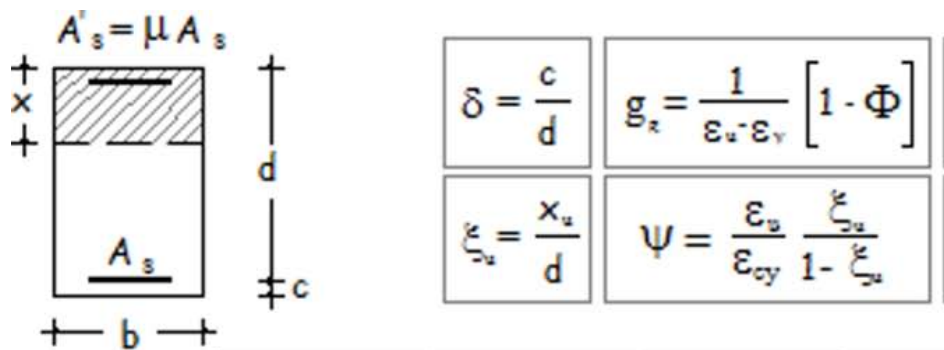

\begin{tabular}{|c|c|}
\hline $\mathrm{g}_{w}=\mathrm{g}_{\mathrm{z}} \varepsilon_{\mathrm{u}}$ & $\mathrm{g}_{\mathrm{u}}=\mathrm{g}_{\mathrm{z}} \varepsilon_{\mathrm{su}}$ \\
\hline$\omega=\frac{A_{s} f_{y}}{b d f_{c}}$ & $\frac{\kappa \xi_{\mu}}{\beta-\mu \beta^{\prime}}$ \\
\hline
\end{tabular}

$\beta_{0}=1+\varepsilon_{y} g_{z}$
$\bar{\omega}=\frac{\omega}{\alpha}=\frac{\kappa \xi_{u}}{\beta-\mu \beta^{\prime}}$

\begin{tabular}{|c|c|c|c|c|}
\hline & $\varepsilon$. & a. & $\kappa_{0 *}$ & $\kappa_{:}$ \\
\hline$*=y$ & $\varepsilon_{y}$ & 1 & 0 & 0 \\
\hline$*=\mathrm{cr}$ & $\varepsilon_{c r}$ & $1+\delta$ & $\frac{2}{3 \alpha} \alpha$ & $\kappa_{0 *}$ \\
\hline
\end{tabular}

Fig. (6) also summarises the procedure used to obtain $\xi_{c r}$

\subsection{Step 2: $\xi_{c r}, \xi_{y}$ and $\xi_{u}$.}

In order to obtain these functions, it is convenient to introduce three different patterns of the strain distribution at cracking or yielding (namely A, B or C), whose definition can be deduced from Fig. (7). In the same figure the values of $\xi_{*_{A}}, \xi_{*_{B}}$ and $\xi_{*_{C}}$ are also shown (neutral axis depth for "cr" or " $y$ " at limits of fields A, B or C). Equation (*) allows to obtain the correlative $\xi_{u A}, \xi_{u B}$ and $\xi_{u C}$ (neutral axis depth at ULS for the same $\omega$ ). In addition, it is appropriate to introduce the parameters reported in Table $\mathbf{1}$. and $\xi_{y}$ vs $\xi_{u}$. Once the generic value for $\xi_{u}$ and $\mu$ is fixed, the translation equilibrium equation allows to calculate the correlative mechanical reinforcement ratio $\omega$ by equation $\left({ }^{(* *)}\right.$ see Fig. 6). For the same values $\xi_{u}$ and $\mu$, the corresponding translation equilibrium equation at " $c r$ " or " $y$ " (differentiated for strain distributions A, B or C) allows to deduce an alternative expression for $\omega\left({ }^{(* * *)}\right.$ - see Fig. 6). By equating $\left({ }^{(* *)}\right.$ see Fig. 6) and $\left({ }^{(* *)}-\right.$ see Fig. 6) it is possible to obtain the searched relation between $\xi_{c r}$ (or $\xi_{y}$ ) and $\xi_{u}(14)$ :

$$
\frac{k \xi_{u}}{\beta-\mu \beta^{\prime}}=\frac{\left(k_{*}+k_{0^{*}}\right) \xi_{*}-k_{1^{*}}}{\beta_{*}-\mu \beta^{\prime}}
$$




\subsection{Step 3: Evaluation of $\xi_{u} v s \xi_{u}^{\text {conv }}$.}

The procedure used to obtain these functions, similarly to Step 2, introduces three different patterns of the strain distribution at ULS (1, 2 or 3, see Fig. 7). These distributions are obtained considering the "conventional" constitutive laws of
Fig. (6). The quantities $\xi_{u 1}, \xi_{u 2}$ and $\xi_{\text {u3 }}$ (or, equivalently $\omega_{1}$, $\left.\omega_{2}, \omega_{3}\right)$ represent the limits of these patterns (equation ${ }^{\left({ }^{\circ}\right)}$ see Fig. 7). Afterwards, fixing the generic values for $\xi_{u}$ and $\mu$, the translation equilibrium equation allows to obtain the correlative mechanical reinforcement ratio $\omega$ by means equa-

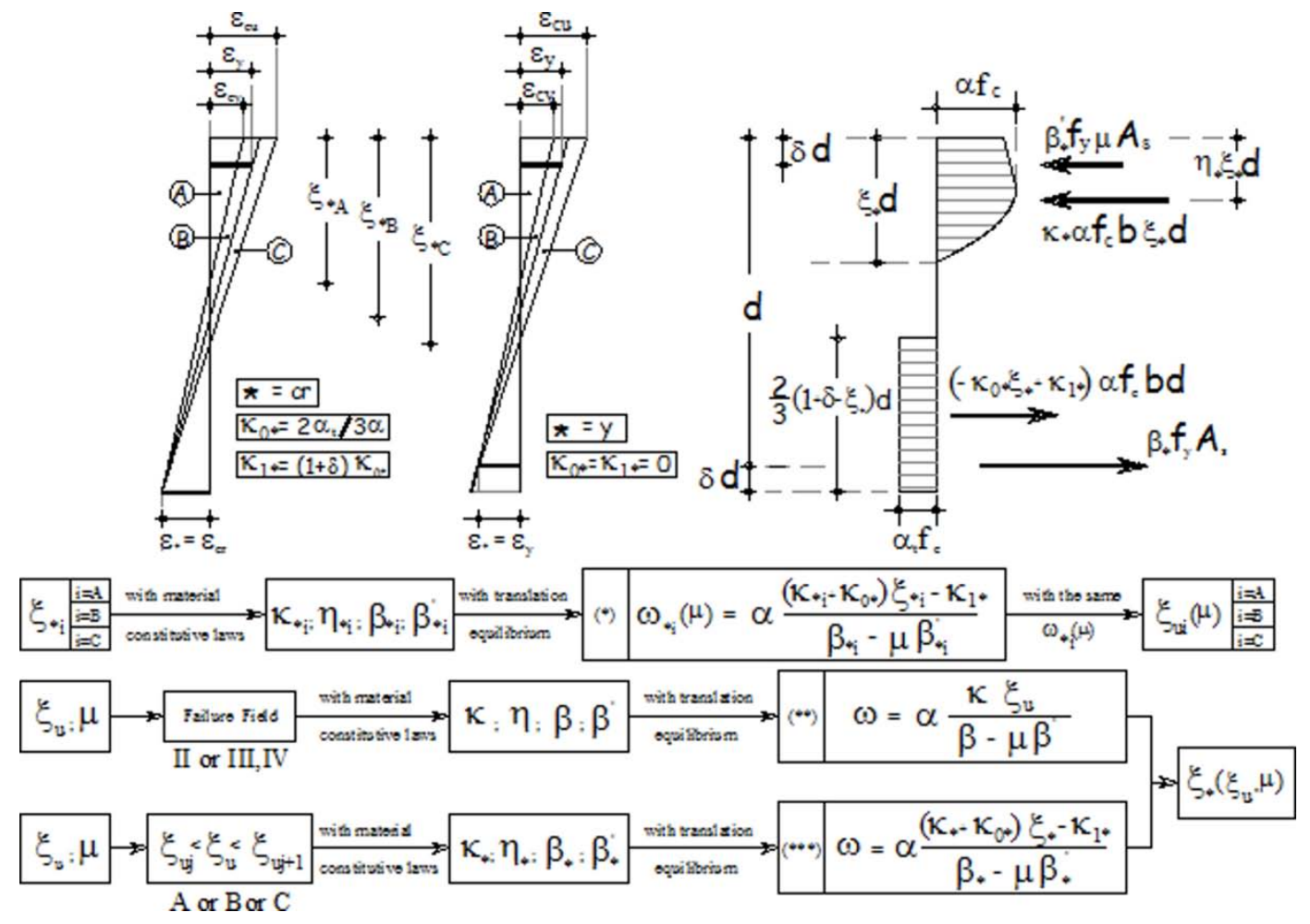

Fig. (6). Procedure used to obtain $\xi_{c r}$ and $\xi_{y}$ vs $\xi_{u \text {.. }}$
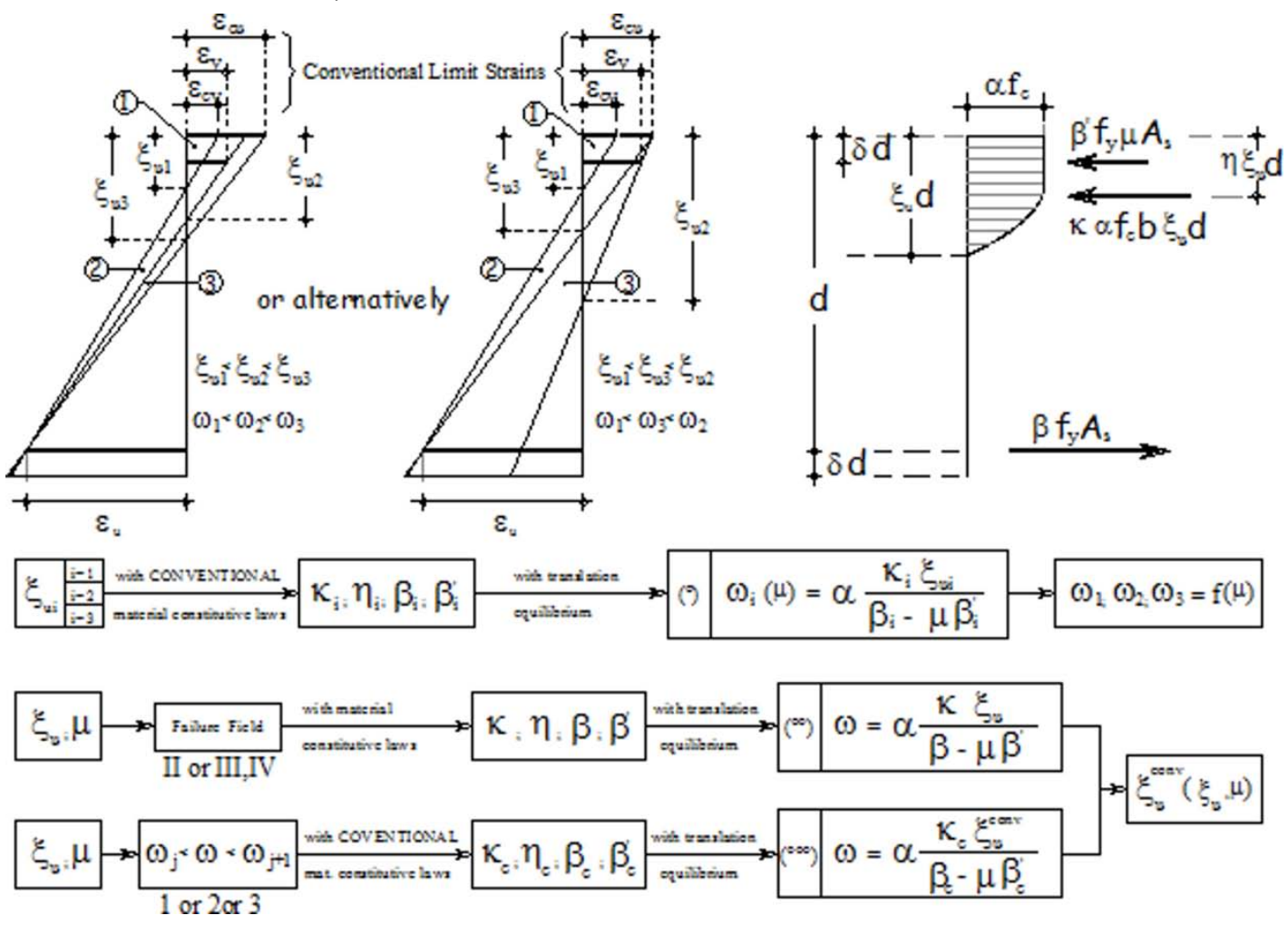

Fig. (7). Procedure used to obtain $\xi_{u}$ vs $\xi_{u}^{\text {conv }}$ 
tion $\left({ }^{\left({ }^{\circ}\right)}\right.$ - see Fig. 7), considering the activated failure field II,III or IV for the "conventional" constitutive law. For the same values $\xi_{u}$ and $\mu$, the corresponding translation equilibrium equation allows to deduce an alternative expression for $\omega\left({ }^{(00)}\right.$ - see Fig. 7) with "actual" constitutive law. By equating $\left({ }^{\left({ }^{\circ}\right),\left({ }^{\circ 00}\right)}\right.$ - see Fig. 7), it is possible to obtain the searched relation between $\xi_{u}$ and $\xi_{u}^{\text {conv }}$.

$\frac{k \xi_{u}}{\beta-\mu \beta^{\prime}}=\frac{k_{c} \xi u}{\beta-\mu \beta^{\prime}}$

In order to provide a complete overview about the several parameters involved in the procedure shown in the present and previous paragraphs, see Appendix in the end of the document.

On the basis of the procedure shown above and the following Fig. (8), $\xi_{u}^{\text {conv }}$ is given by three numerical relationships depending on the failure fields considered for the rectangular cross section.

\section{RESULTS}

\subsection{Influence of Tension Stiffening and Concrete in Tension}

The analytical formulation here proposed with a numerical model was compared. Model takes into account the tensile concrete strength and effects of tension stiffening. The purpose of the comparison is the evaluation of the level of approximation involved by the proposed formulation.

Fig. (9) and Fig. (10) report the results of the comparison between the two approaches, which seem to be very close. The diagrams refer to rectangular cross section beams, reinforced with steel characterised by $\varepsilon_{y}=0.27 \% ; \varepsilon_{u}=$ $5 \% ; f_{t} / f_{y}=1.08$. The concrete has been modelled through two different constitutive laws: the first one refers to non confined concrete, with $\varepsilon_{\mathrm{cr}}=0.025 \%, \quad \varepsilon_{\mathrm{cy}}=0.2 \%$ and $\varepsilon_{\mathrm{cu}}=0.35 \%$, the second one to confined concrete described by the usual Kent-Park model [17](Kent and Park, 1971), with $\varepsilon_{\mathrm{cr}}=0.025 \%, \varepsilon_{\mathrm{cy}}=0.2 \%$ and $\varepsilon_{\mathrm{cu}}=0.878 \%$, and where:

$\rho=\frac{2\left(b^{\prime \prime}+d^{\prime \prime}\right) \omega_{s t}}{\left(b^{\prime \prime} d^{\prime \prime}\right) s_{s t}}=0.002769$

is the volumetric ratio of confining hoops.

It should be pointed out, remembering the assumptions made preliminarily, that the disregarded effects seem to have a certain importance for the evaluation of the sectional ductility. Especially if compared to parameters as the transversal reinforcement ratio or compressive reinforcement ratio that contribute to grow up the ultimate rotation capacity.

The plots in Fig. (10) also show that the softening branch has the effect to maintain the maximum of the ductility to very high values of the mechanical reinforcement ratio $\omega$, when combined with suitable values of the compressive longitudinal reinforcement.

\subsection{Plastic Rotation Capacity of Beams with Rectangular Cross section}

The plastic rotation capacity of rectangular cross section is reported in Fig. (11a) for concrete constitutive law considering parabolic softening branch, while, in Fig. (11b), for concrete constitutive law having linear softening branch. The main parameters are: material properties, shear slenderness $(\lambda=3)$, compressive reinforcement steel ratio $\mu$, conventional neutral axis depth $\xi_{u}^{\text {conv }}$. The $\theta_{P}$ vs $\xi_{u}^{\text {conv }}$ relationship, indicated in red in Figs. (11a and 11b), corresponds to the specific case of concrete rectangular cross section with $f_{c}=25 M p a$ and $\mu=0.5$.

Bending and shear contributions are separately plotted in the diagram, together with the related procedure that allows to detect the value of $\xi_{\mathrm{lim}}$. With this procedure it is also possible to evaluate the effects of the shear cracking.

The graphical approach confirms the importance to have a detailed assessment of $\xi_{\mathrm{lim}}$. In fact, the contribution of the shear cracking seems to be absolutely not negligible for the sectional ductility.

With regard to the confinement effects, Figs $(9,10,11 a$ and 11b) show that, for failure of the compressive zone ( $\theta_{p}$ decreasing with $\xi_{u}$ ), the rotational capacity highly depends on the concrete confining degree. Moreover, ductility strongly decreases because the tensile reinforcement ratio $\omega$ becomes higher, whereas it increases together with compressive reinforcement.

\subsection{Comparison with MC2010 and EC2}

Finally, in Fig. (12) (left) comparison with the diagrams provided by EC2 and MC2010 is carried out $(\lambda=3)$. The materials considered are: concrete $C 25 / 30$, steel "Type A" (MC2010)[18] or "Class B" (EC2), with $\varepsilon_{y}=0.27 \%, \varepsilon_{u}=$ $5 \%, \Phi=f t / f y=1.08$. The maximum values are attained for a $\xi_{u}^{\text {conv }}$ between $12 \%$ and $15 \%$. In Fig. (12) (right) for a volumetric ratio of confining hoops $\rho=0.002769$ (see Equation 17), to the allowable plastic rotation exhibit a sudden jump to the value of $50 \mathrm{mrad}$, which remains quasi-constant for a wide range of $\xi_{u}^{\text {conv }}$.

\section{FINAL REMARKS}

The plastic rotation capacity must be determined in order to check if critical sections have the sufficient ductility to redistribute internal forces and avoid brittle failure. Usually, international codes provide graphical approaches that appear to be an inadequate design tool because of their several approximations. More accurate formulations are indeed necessary, especially to give suggestions finalized to geometrical dimensioning and arrangement of the reinforcing.

The proposed model includes the influence of the most relevant factors on the calculation of the rotational ductility and allows to focus the attention on the importance that each of them has in addressing the structural failure to a ductile behaviour. 


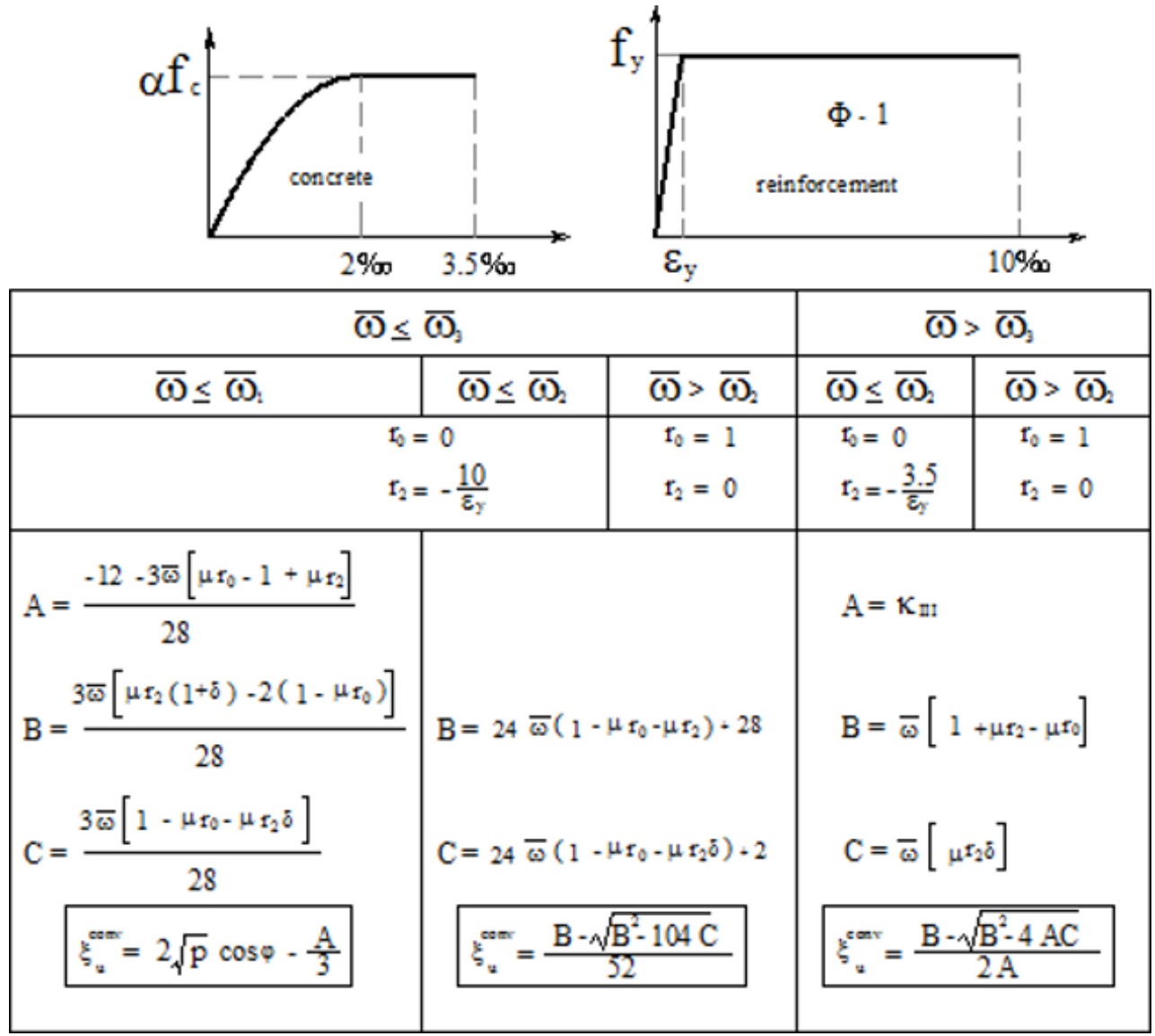

Fig. (8). Relationships of the $\xi_{u}^{\text {conv }}$ for conventional constitutive laws of the materials.
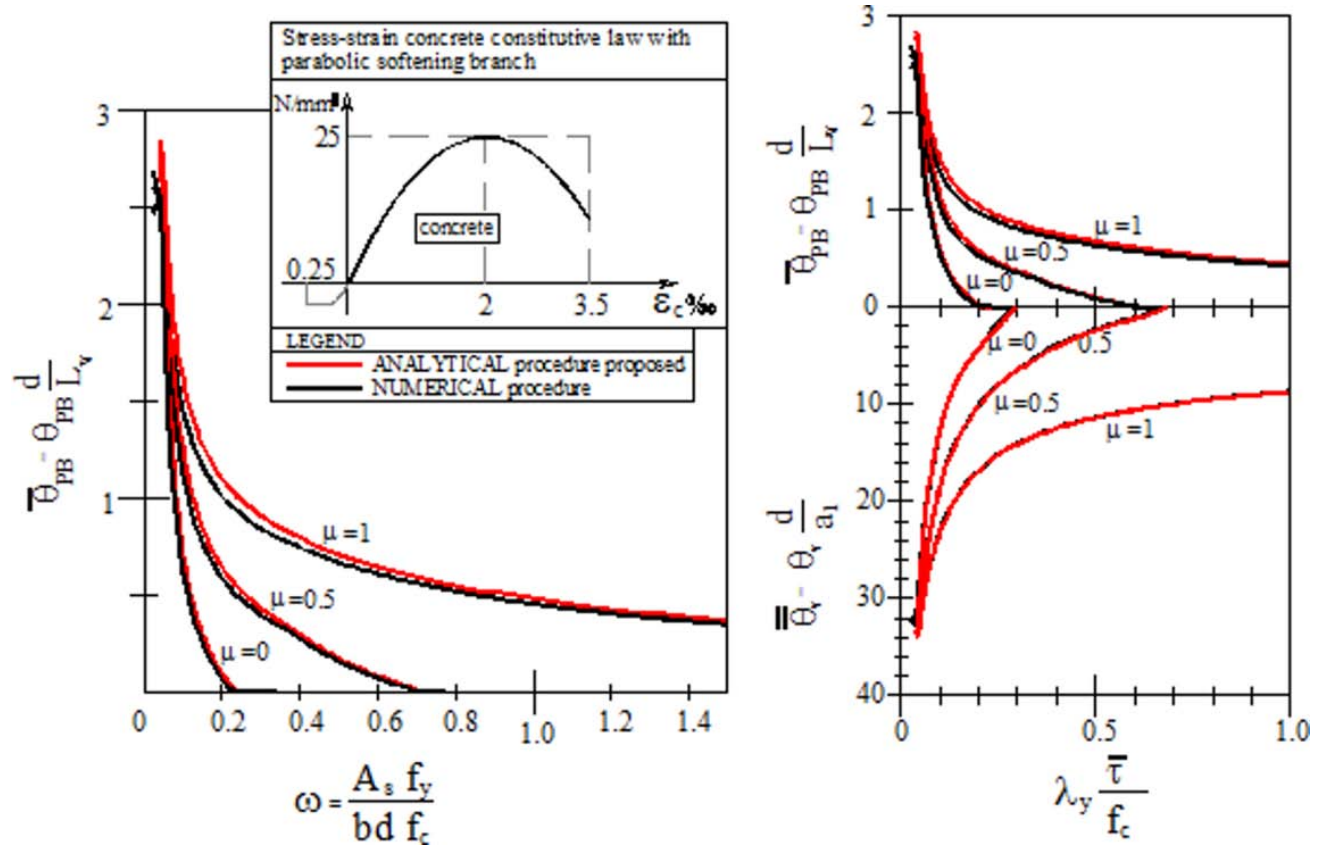

Fig. (9). Plastic rotation capacity according to the concrete constitutive law with parabolic softening branch and non confined concrete.

Around the following fundamental parameters:

- Concrete and reinforcement constitutive law (§ 2.1, Fig.

1) $\mathrm{f}_{\mathrm{c}}, \varepsilon_{\mathrm{cy}}, \varepsilon_{\mathrm{cu}}, \alpha, \alpha_{\mathrm{t}}, \gamma, \varepsilon_{y}, \varepsilon_{u}$ and $\Phi$; - eventually;

- Material strength ratio $f_{c} / f_{y}$;
- Dimensionless concrete cover: $\delta=c / d$;

- Mechanical reinforcement ratio: $\omega=\frac{A_{s} f_{y}}{b d f_{c}}$;

- Compressive reinforcement ratio: $\mu=A_{S}{ }^{\prime} / A_{S}$;

- Shear slenderness: $\lambda=L_{V} / d$; 


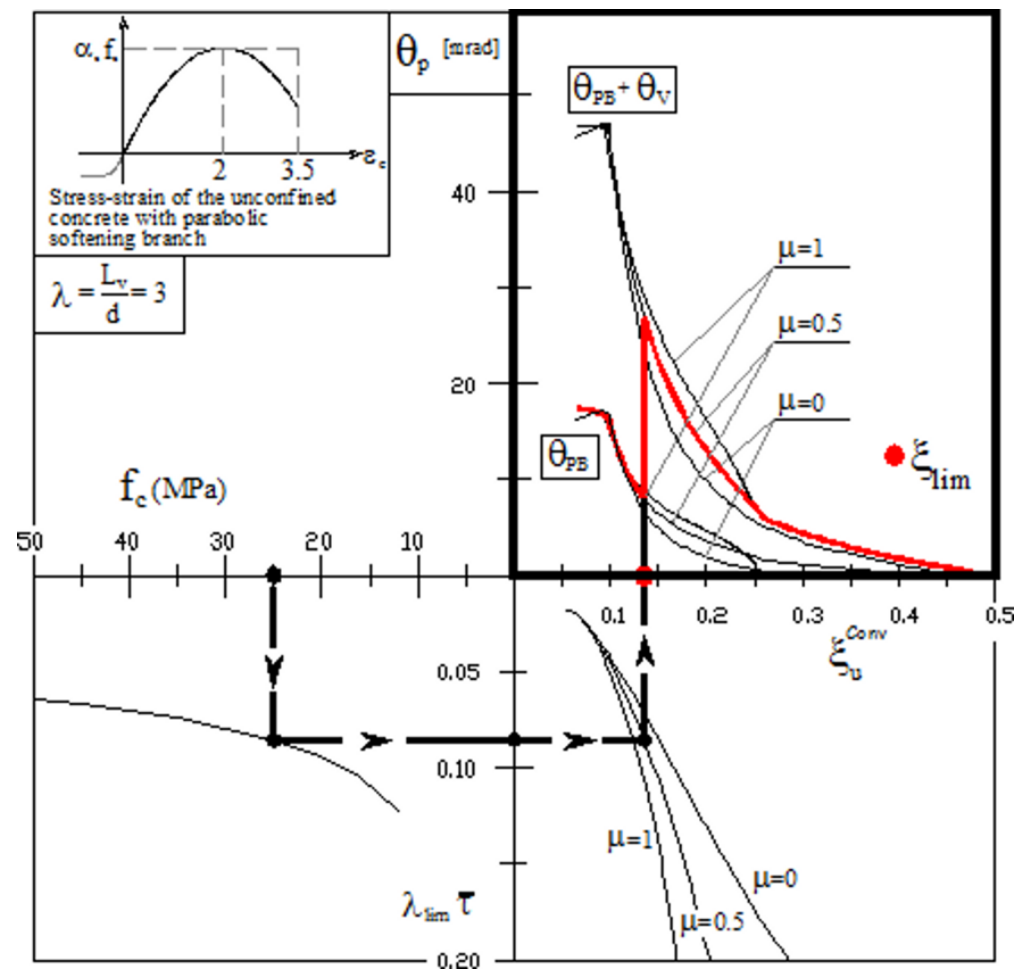

Fig. (11a). Rotation capacity due to bending $\left(\theta_{P B}\right)$ and shear $\left(\theta_{V}\right)$ for constitutive law with parabolic softening branch and unconfined concrete.

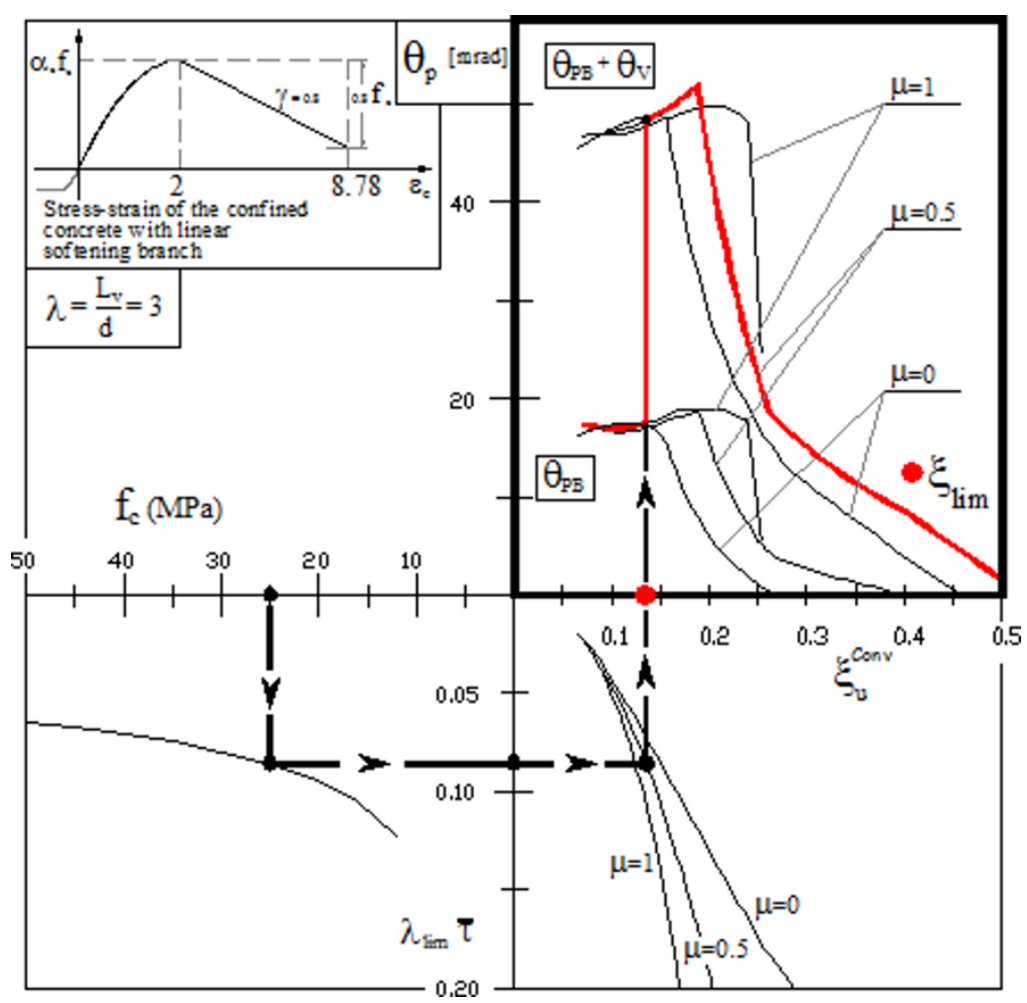

Fig. (11b). Rotation capacity due to bending $\left(\theta_{P B}\right)$ and shear $\left(\theta_{V}\right)$ for constitutive law with linear softening branch and confined concrete.

The procedure can be summarized as follows:

1. $\xi_{u}^{\text {conv }}=(x / d)^{c o n v}$ is obtained from geometric and material parameters;

2. $\xi_{u}$ vs $\xi_{u}^{\text {conv }}$ is obtained through the procedure shown in
Fig. (7), Equation 16, reported in §4.3;

3. $\xi_{c r}$ and $\xi_{y}$ vs $\xi_{u}$ are obtained through the procedure shown in Fig. (6), Equation 13 reported in §4.2;

4. $X_{c r}, X_{y}$ and $X_{u}$ vs $\xi_{c r}$ and $\xi_{y}$ vs $\xi_{u}$, are respectively calcu- 

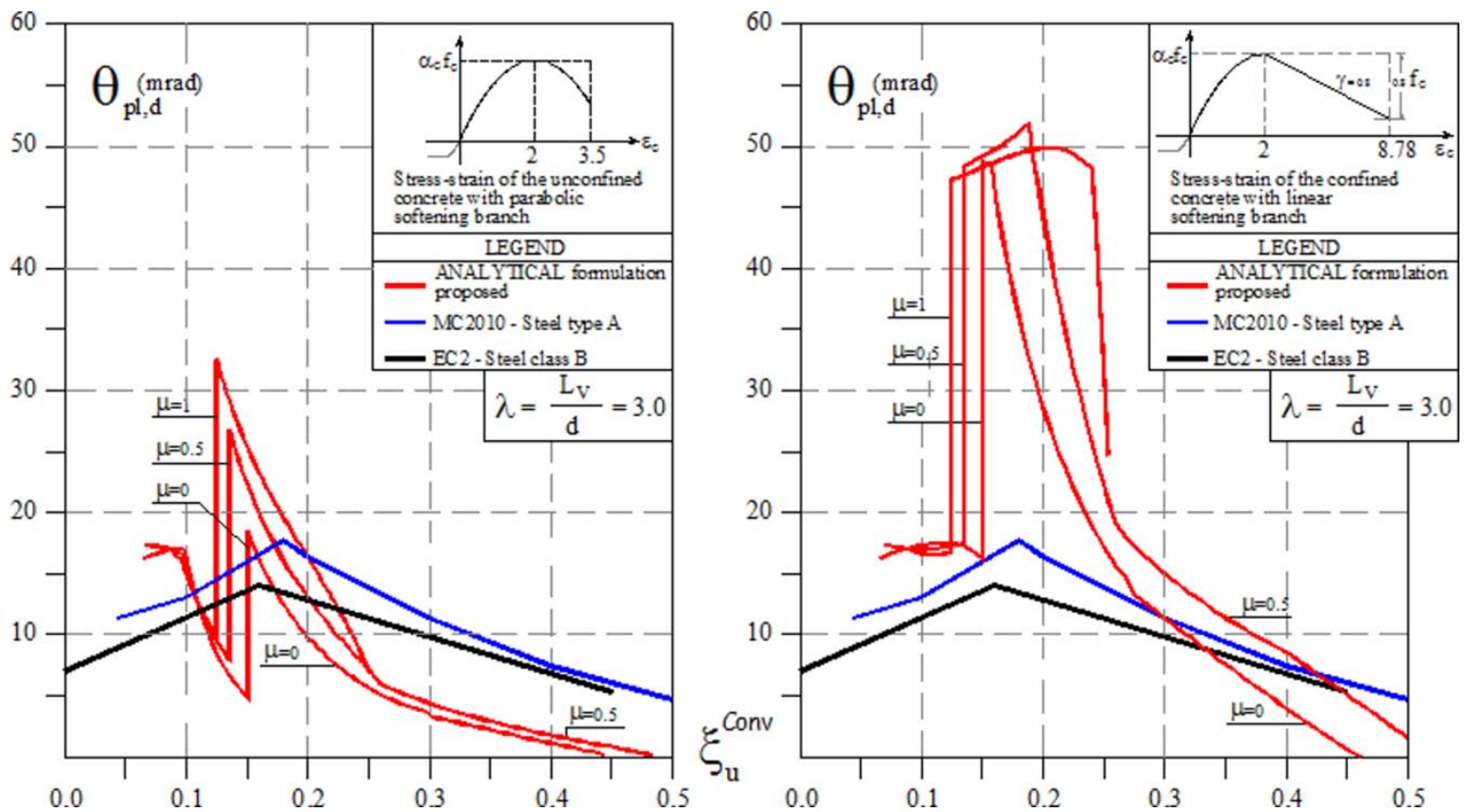

Fig. (12). Plastic rotation capacity as a function of $\xi_{u}^{\text {conv }}$ and comparison with MC2010 and EC2, (left) for unconfined concrete, (right) for confined concrete.

lated from Equations 11,12,13 and 14 reported in $\S 4.1 ; \quad \Phi \quad=$

5. $\theta_{P B}$ and $\theta_{V}$ are calculated from Equations 6 and 7 reported in $\S 3$;

6. Finally, the plastic rotation capacity is obtained as the sum of bending and sher components:

$\theta_{P}\left(\xi_{u}^{\text {conv }}\right)=\theta_{P B}\left(\xi_{u}^{\text {conv }}\right)+\theta_{V}\left(\xi_{u}^{\text {conv }}\right)$

\section{NOMENCLATURE}

$a_{1}=$ coefficient of the Ahner and Kliver model (1998) [15]

$A_{s} \quad=\quad$ area of tension reinforcement

$A_{s}{ }^{\prime}=$ area of compression reinforcement

$b \quad=\quad$ width of rectangular cross section

$b$, = width of the confined core of the cross-section

$d^{\prime \prime}=$ depth of the confined core of the cross-section

$E_{s} \quad=\quad$ Young's modulus of steel

$f_{c}=$ concrete compressive strength

$f_{t} \quad=\quad$ ultimate strength of reinforcement

$f_{y} \quad=\quad$ yield strength of reinforcement

$h=$ cross-sectional depth

$k=$ filling coefficient

$L_{V} \quad=\quad$ shear span

$M_{c r}=$ bending moment at cracking

$M_{u}=$ bending moment at collapse (ultimate)

$M_{y} \quad=\quad$ bending moment at yielding

$x=$ neutral axis depth $\alpha \quad=$

$\alpha_{t} \quad=$

$\alpha_{t} \quad=$

$\beta \quad=$

$\beta^{*} \quad=$

$\beta_{S}=$

$\delta d=$

$\varepsilon_{c r} \quad=$

$\varepsilon_{c u} \quad=$

$\varepsilon_{c y} \quad=$

$\varepsilon_{u} \quad=$

$\varepsilon_{y} \quad=$

$\gamma \quad=$

$\lambda=$

$\lambda_{\lim }=$

$\mu \quad=$ ratio between ultimate and yield strength of reinforcement

multiplicative factor of the concrete compressive strength

inclination of the stirrup reinforcement (Ahner and Kliver model (1998) [15])

multiplicative factor of the concrete compressive strength in order to evaluate the concrete tensile strength

coefficient that defines the level of reinforcement in tension

coefficient that defines the level of reinforcement in compression

inclination of the compression equivalent strut in the shear model

concrete cover (also as “c”)

concrete cracking strain

concrete ultimate strain

concrete yielding strain

ultimate strain of reinforcement

yield strain of reinforcement

strength loss in the softening branch $(0<\gamma<1)$

shear slenderness

limit shear slenderness

ratio between tensile and compression steel reinforcement 
$\theta_{P B}=$ plastic bending rotation

$\theta_{V}=$ shear plastic rotation

$\rho_{l}=$ steel percentage ratio of longitudinal reinforcement

$\tau_{r} \quad=\quad$ threshold shear - according to Bullettin CEB (1985) [16]

$\xi_{c r}=$ normalized neutral axis depth at cracking

$\xi_{u}=$ normalized neutral axis depth at ultimate

$\xi_{u}^{\text {conv }}=$ conventional value of normalized neutral axis depth at ultimate

$\xi_{y} \quad=\quad$ normalized neutral axis depth at yielding

$\xi=$ normalized neutral axis depth

$\omega=$ mechanical reinforcement ratio of the tension longitudinal reinforcement

$\omega_{s t}=$ mechanical reinforcement ratio of the stirrup reinforcement
$\overline{\theta_{P B}}=$ dimensionless plastic bending rotation

$\overline{\theta_{u}}=$ dimensionless plastic rotation at ultimate

$\overline{\theta_{y}} \quad=\quad$ dimensionless plastic rotation at yielding

$\overline{\chi_{c r}}=$ dimensionless curvature of first cracking

$\overline{\chi_{u}}=$ dimensionless curvature at collapse point

$\overline{\chi_{y}}=$ dimensionless curvature at yielding point

\section{CONFLICTS OF INTEREST}

The authors confirm that this article content has no conflicts of interest.

\section{ACKNOWLEDGEMENT}

The research presented in this article was partially funded by the Department of Civil Protection, Project ReLUIS-DPC 2010-2013.

\section{APPENDIX}

In the following Figures, the values of the main parameters that define the whole procedure were reported. The values are related to the constitutive laws for the concrete with linear and parabolic branch, whereas for reinforcement bars the law is elastic-plastic with and without hardening. The figures are to be considered as a small guideline to the steps of the procedure described in sections 4.2 and 4.3 .

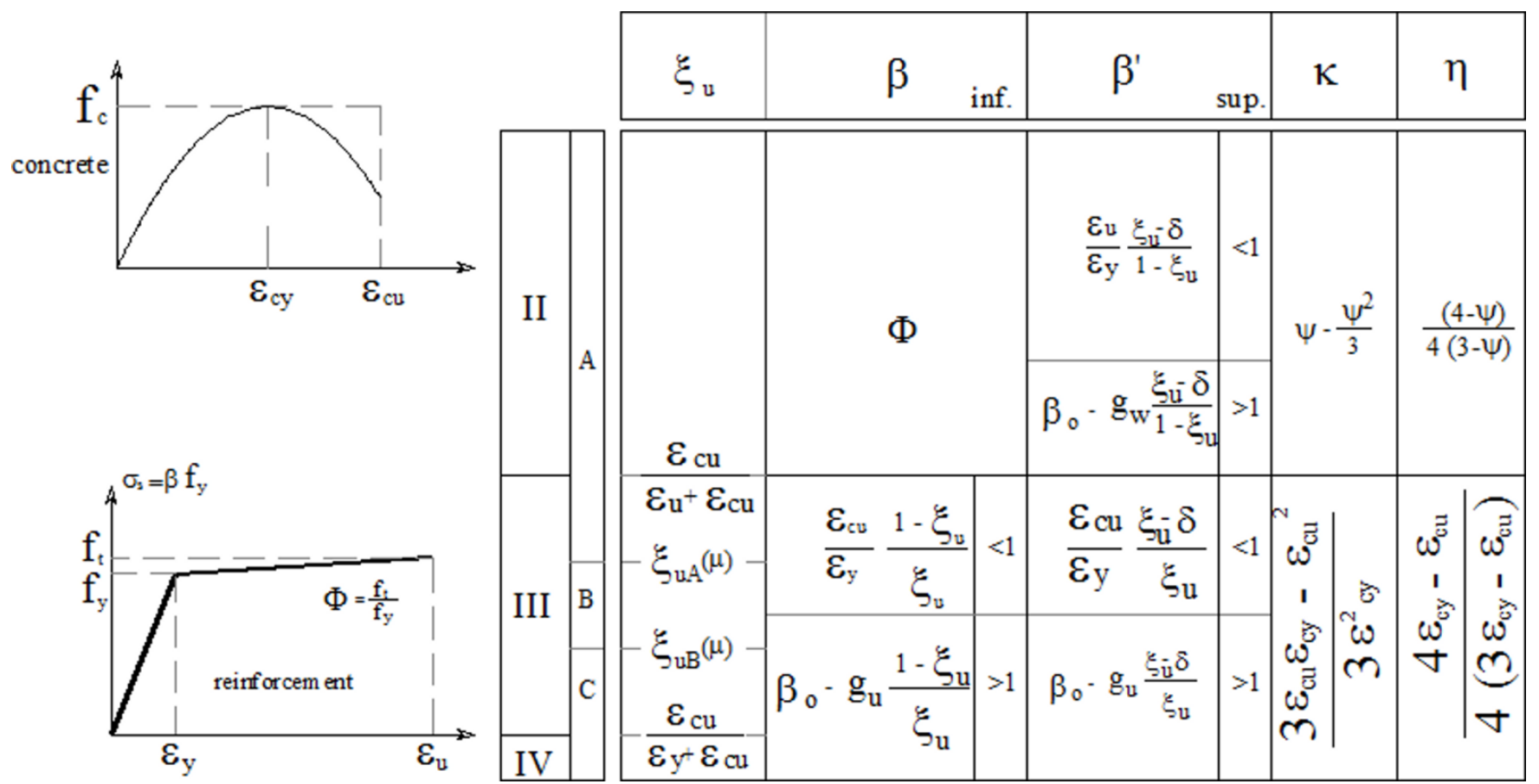

Fig. (A1). Coefficient values $\eta, \kappa, \beta, \beta$, for the constitutive law of the concrete with parabolic softening branch and elastic-plastic with hardening for the reinforcement. 


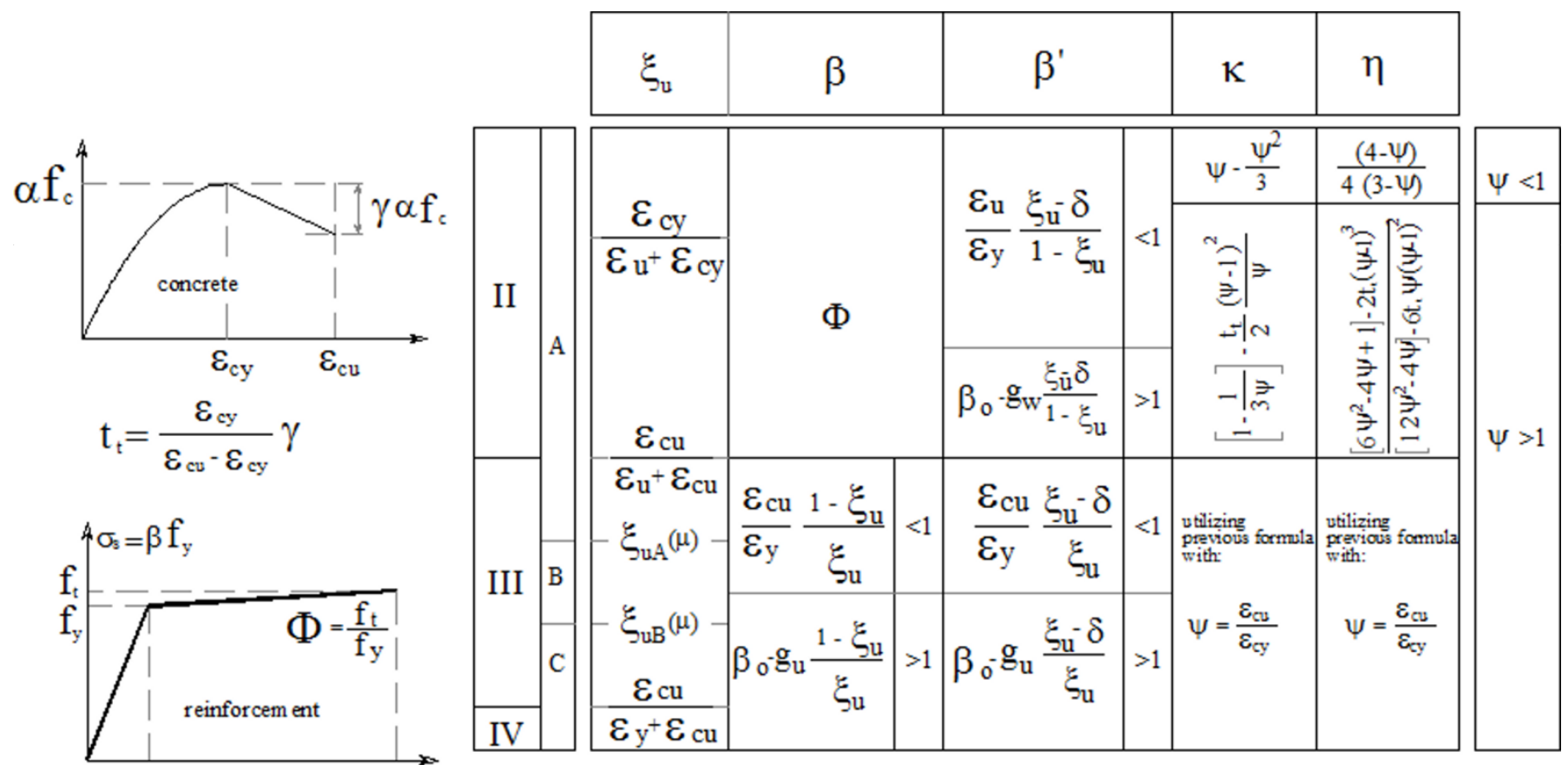

Fig. (A2). Coefficient values $\eta, \kappa, \beta, \beta$ ' for the constitutive law of the concrete with linear softening branch and elastic-plastic with hardening for the reinforcement.

\section{REFERENCES} 2363, 2007
CEN. Eurocode 8: Design provisions for earthquake resistance of structures -- Part 3: assessment and retrofitting of buildings. European Committee for Standardisation EN1998-3, Brussels, Belgium, 2005.

CEN. Eurocode 2: Design of Concrete Structures - Part 1-1: General rules and rules of buildings. European Prestandard, EN 1992-1-1, Brussels, Belgium, 2005.

CEB-FIB. Seismic assessment and retrofit of reinforced concrete buildings. CEB-FIB Bulletin no. 24. International federation for structural concrete, task group 7.1, Lausanne, 2003.

T. B. Panagiotakos and M.N. Fardis, "Deformation of reinforced concrete members at yielding and ultimate" ACI Structural Journal, vol. 98, no. 2, pp. 135-148, 2001.

T. Rossetto, "Prediction of deformation capacity of nonseismically designed reinforced concrete members". In: Proceedings of the 7th U.S. national conference on earthquake engineering, Boston, July 21-25, 2002.

S.E.E Lam, B. Wu, Y. L. Wong, Z. Y. Wang ZY, Z. Q. Liu and C. $\mathrm{S}$. Li, “'Drift capacity of rectangular reinforced concrete columns with low lateral confinement and high-axial load". ASCE Journal Structural Engineering, vol. 129, no. 6, pp. 733-742, 2003.

I. Perus and P. Fajfar "Prediction of the force-drift envelope for RC columns in flexure by the CAE method", Earthquake Engineering \& Structural Dynamics, vol. 36, no. 15, pp. 2345-

I. Perus, K. Poljansek and P. Fajfar, "Flexural deformation capacity of rectangular RC columns determined by the CAE method", Earthquake Engineering \& Structural Dynamics, vol. 35, no. 12, pp. 1453--1470, 2006
[9] M. N. Fardis, LESSLOSS,---risk mitigation for earthquakes and landslides. Guidelines for displacement based design of buildings and bridges, Report No. 5/2007. IUSS Press, Pavia, Italy, 2007.

[10] L. Zhu, K. J. Elwood, T. Haukaas, "Classification and seismic safety evaluation of existing reinforced concrete columns", ASCE Journal Structural Engineering, vol. 133, no.9, pp. 1316-1330, 2007.

[11] G. Uva, F. Porco, A. Fiore, Appraisal of masonry infill walls effect in the seismic response of RC framed buildings: a case study. Engeneering Structures, vol. 34, no. 1, pp. 514-26, 2012.

[12] A. Fiore, F. Porco, D. Raffaele, G. Uva, About the influence of the infill panels over the collapse mechanisms actived under pushover analyses: two case studies. Soil Dynamics and Earthquake Engineering, vol. 39, pp. 11-22, 2012.

[13] G. Uva, F. Porco, D. Raffaele, A. Fiore, On the role of equivalent strut models in the seismic assessment of infilled RC buildings. Engineering Structures, vol. 42, pp. 83-94, 2012.

[14] D. Raffaele, F. Porco, A. Fiore, G. Uva, "Simplified Vulnerability Assessment of RC Circular Piers in Multi-Span-Simply Supported Bridges”, Structure and Infrastructure Engineering, 2013DOI:10.1080/15732479.2013.772642.

[15] C. Ahner and J. Kliver, "Development of a new concept for the Rotation Capacity in DIN 1045" 1998 Part I, LACER no. 3, pp. 213-236, Universitat Leipzing.

[16] CEB Bulletin Manual on Cracking and Deformation. Bulletin d'Information n. 158E, Lausanne; 1985.

[17] D.C. Kent, R. Park, "Flexural members with confined concrete", Journal of the Structural Division, ASCE, July 1971: pp. 19691990.

[18] Model Code 2010 - Final draft, International Federation for Structural Concrete (fib), Bulletin d'Information n. 66, Lausanne, Switzerland; 2010.

(C) Raffaele et al.; Licensee Bentham Open.

This is an open access article licensed under the terms of the Creative Commons Attribution Non-Commercial License (http://creativecommons.org/licenses/ by-nc/3.0/) which permits unrestricted, non-commercial use, distribution and reproduction in any medium, provided the work is properly cited. 